NBER WORKING PAPER SERIES

\title{
LIFECYCLE PORTFOLIO CHOICE WITH SYSTEMATIC LONGEVITY RISK AND VARIABLE INVESTMENT-LINKED DEFERRED ANNUITIES
}

\author{
Vasily Kartashov \\ Raimond Maurer \\ Olivia S. Mitchell \\ Ralph Rogalla \\ Working Paper 17505 \\ http://www.nber.org/papers/w17505 \\ NATIONAL BUREAU OF ECONOMIC RESEARCH \\ 1050 Massachusetts Avenue \\ Cambridge, MA 02138 \\ October 2011
}

This research reported herein was performed pursuant to a grant from the TIAA-CREF Research Institute. Additional research support was provided by the German Science Association (DFG), German Investment and Asset Management Association (BVI), the Pension Research Council at The Wharton School of the University of Pennsylvania, and the Metzler Exchange Professor program. We thank Moshe Milevsky and participants of the Longevity Risk 7 Conference in Frankfurt for valuable comments. This research is part of the NBER programs on Aging, Public Economics, and Labor Studies. Opinions and errors are solely those of the authors and not of the institutions with whom the authors are affiliated. The views expressed herein are those of the authors and do not necessarily reflect the views of the National Bureau of Economic Research.

At least one co-author has disclosed a financial relationship of potential relevance for this research. Further information is available online at http://www.nber.org/papers/w17505.ack

NBER working papers are circulated for discussion and comment purposes. They have not been peerreviewed or been subject to the review by the NBER Board of Directors that accompanies official NBER publications.

(C) 2011 by Vasily Kartashov, Raimond Maurer, Olivia S. Mitchell, and Ralph Rogalla. All rights reserved. Short sections of text, not to exceed two paragraphs, may be quoted without explicit permission provided that full credit, including $\odot$ notice, is given to the source. 
Lifecycle Portfolio Choice with Systematic Longevity Risk and Variable Investment-Linked

Deferred Annuities

Vasily Kartashov, Raimond Maurer, Olivia S. Mitchell, and Ralph Rogalla

NBER Working Paper No. 17505

October 2011

JEL No. G11,G2,G22,G23,H55,I3

\section{ABSTRACT}

This paper assesses the impact of variable investment-linked deferred annuities (VILDAs) on lifecycle consumption, saving, and portfolio allocation patterns given stochastic and systematic mortality. Insurers have taken two approaches to manage systematic mortality risks, namely self-insurance and risk transfer to purchasers of the annuity products. We demonstrate that self-insurance leads to high loadings, so that households offered a choice would favor the risk transfer scheme. Reservation loadings on the actuarially fair VILDA price for non-participation are $0.5-8 \%$; if insurers cannot hedge within this range, they will transfer systematic longevity risks to the annuitants. Our findings have implications for new payout products that may be attractive to older households seeking to protect against retirement shortfalls.

Vasily Kartashov

Finance Department

Goethe University

Grueneburgplatz 1 (Uni-PF. H 23)

Frankfurt am Main

Germany

kartashov@finance.uni-frankfurt.de

Raimond Maurer

Finance Department

Goethe University

Grüneburgplatz 1 (Uni-PF. H 23)

Frankfurt am Main

Germany

rmaurer@wiwi.uni-frankfurt.de
Olivia S. Mitchell

University of Pennsylvania

Wharton School

3620 Locust Walk, St 3000 SH-DH

Philadelphia, PA 19104-6302

and NBER

mitchelo@wharton.upenn.edu

Ralph Rogalla

Finance Department

Goethe University

Grüneburgplatz 1 (Uni-PF. H 23)

Frankfurt am Main

Germany

rogalla@wiwi.uni-frankfurt.de 


\section{Lifecycle Portfolio Choice with Systematic Longevity Risk and Variable Investment-Linked Deferred Annuities}

\section{Introduction}

Many defined contribution pension plans currently do not offer access to annuities during the accumulation or the decumulation phase. ${ }^{1}$ Indeed, most product innovation in the last decade has focused on the accumulation phase seeking to attract and diversify workers' retirement saving via target maturity date and balanced funds (c.f. Gomes, Kotlikoff and Viceira 2008). Yet attention is now turning to the decumulation phase, so financial advisers can help their clients manage their portfolio drawdown process during retirement. Previous research on dynamic portfolio choice over the lifecycle suggests that payout annuities with immediate and life-contingent benefit streams are key to protect the consumption needs of risk-averse households having uncertain lifetimes. ${ }^{2}$ Yet despite the theoretical attractiveness of payout annuities, many consumers are reluctant to annuitize their wealth voluntarily. ${ }^{3}$ Explanations for the divergence between theoreticallypredicted and actual behavior include incomplete annuity markets, bequest motives, high costs charged by life annuity providers, and behavioral factors. ${ }^{4}$ Nevertheless, some advocates of annuitization have proposed that annuities be used as a default option in tax-sheltered pension plans.

\footnotetext{
${ }^{1}$ Benartzi, Previtero, and Thaler (2011) note that only 21 percent of defined contribution plans in the U.S. even offer annuities as an option.

${ }^{2}$ The seminal research by Yaari (1965) has been followed by a long list of authors; most recently see Davidoff, Brown, and Diamond (2005) and Horneff, Maurer, Mitchell and Stamos (2009, 2010).

${ }^{3}$ In 2011 sales of fixed annuities stood at only $\$ 20$ billion and of variable annuities $\$ 40$ billion (LIMRA 2011), as compared to over $\$ 18$ trillion in retirement assets (ICI 2011).

${ }^{4}$ Schaus (2005) noted that fewer than one out of ten defined contribution participants opted for an annuity when it was available. Recent reviews of the literature include Horneff, Maurer, Mitchell and Dus (2007); Hu and Scott (2007); and Yagi and Nishigaki (1993).
} 
For this reason, deferred life annuities are now attracting attention from policymakers, regulators, and financial intermediaries. ${ }^{5}$

As with immediate payout annuities, deferred annuities promise lifelong periodic payments to the annuitant in exchange for a non-refundable premium. Whereas the immediate annuity begins paying from the date of purchase, a deferred annuity starts paying benefits as of some pre-specified future date. Due to discounting, as well as the possibility that the annuitant might die before payouts start, the deferred payout annuity will be much less expensive than an immediate annuity with identical payouts. Indeed the low price of deferred annuities may help overcome psychological barriers to voluntary annuitization. Milevsky (2005), for example, argues that most individuals will refrain from irreversibly annuitizing substantial lump sums at retirement, independent of their understanding of individual longevity risk.

Previous studies (e.g. Horneff, Maurer, and Rogalla 2010) focus on deferred annuities that pay flat or fixed lifetime benefits. By contrast, here we examine variable investment-linked deferred annuities (VILDAs) which offer both an investment element, in terms of a mutual fundstyle subaccount, and an insurance element, in terms of pooling longevity risks across the retiree group. Payments begin when the deferring period is over and continue for life, while the benefit paid depends on the performance of the underlying asset portfolio (stocks, bonds, or some combination). Our goal is to assess theoretically how households might value these lifecontingent benefit streams over the lifecycle, under a range of different assumptions regarding uncertain longevity risk. First we study how variable investment-linked deferred annuities influence household optimal consumption patterns as well as portfolio allocations across stocks, bonds, and VILDAs in a world with idiosyncratic yet without systematic longevity risk, i.e.

\footnotetext{
${ }^{5}$ For instance Gale, Iwry, John, and Walker (2008) propose automatic annuitization for 401(k) assets when US employees retiree; in Singapore, the government has recently mandated deferred annuitization (Fong, Mitchell, and Koh 2011).
} 
unknown individual lifetimes but non-stochastic mortality tables. Second, we show how results change once we also account for systematic longevity risk, i.e. stochastic variation of general mortality patterns over time.

A large literature has developed over the last two decades seeking to model the stochastic development of human mortality patterns over time. ${ }^{6}$ In their foundational work, Lee and Carter (1992) introduced a simple discrete-time one-factor model for the central death rate and employed it to describe US mortality rates over time. While this model was able to trace the (downward sloping) time trend in mortality, the one-factor approach implies perfect correlation of mortality innovations over all ages, which contradicts empirical evidence. Subsequently developed stochastic mortality models (e.g. Cairns, Blake, and Dowd, 2006b; Renshaw and Haberman 2003), seek to remedy this by taking a multi-factor approach.

Naturally the impact of systematic mortality risk on household welfare depends on how insurers manage and, hence, price systematic longevity risk, and various strategies are available. One approach, feasible only for large diversified providers, is to build up a 'natural' hedge through a second business line reciprocally affected by general mortality developments (such as life insurance; c.f. Milevsky and Promislow 2001, Gatzert and Wesker 2010). McCarthy and Mitchell (2010), however, question the effectiveness of such a hedge in practice. Alternatively, the insurer might seek to hedge this exposure using capital market instruments such as mortality swaps, making fixed payments in exchange for variable payments linked to the development of an underlying survival index. Currently, however, the market for mortality-linked products is still underdeveloped (Blake and Burrows 2001; Cowley and Cummins 2005) so it is questionable

\footnotetext{
${ }^{6}$ For a detailed discussion of alternative approaches see Pitacco, Denuit, Haberman and Olivieri (2009), Cairns, Blake, Dowd (2006a), as well as Cairns, Blake, Dowd, Coughlan, Epstein, and Khalaf-Allah (2010).
} 
whether an insurer with a substantial exposure to systematic mortality risk would be able to purchase an adequate amount of insurance against this sort of longevity risk.

The present paper focuses on two risk management approaches that are independent of firm size and capital market solutions: insurer self-insurance, and risk pool participation. Under the self-insurance strategy, providers will set the VILDA price so that they run little chance that benefits paid to annuitants will exceed provider reserves. Under the risk pool participation approach, the VILDA provider can refrain from taking systematic mortality risks into its books by only offering products which have annuitants participate in the development of general lifeexpectancy by adjusting benefit payments to unanticipated mortality shocks. ${ }^{7}$

The remainder of this paper is organized as follows: Section 2 describes the fundamental characteristics of VILDAs. Section 3 draws out lifecycle implications of including VILDAs in the household portfolio, assuming non-stochastic mortality tables. In the next Section, we introduce systematic longevity risk and its effect on optimal lifecycle behavior. Section 5 concludes.

\section{Variable Investment-Linked Deferred Payout Annuities}

An immediate investment-linked payout annuity is a financial contract between a retiree and a life insurance company, whereby in exchange for paying an initial (non-refundable) premium, the annuitant immediately begins to receive lifelong payments equal to the value of a pre-specified number of units on a specific asset portfolio, usually represented by mutual funds. As payments depend on the value of the annuity funds units (FUs), they can be stochastic when

\footnotetext{
${ }^{7}$ This is similar in spirit to the group self-annuitization model proposed by Piggott, Valdez, and Denzel (2005), and the product on offer by the Teachers Insurance and Annuity Association (TIAA) through its fellow life insurer, the College Retirement Equities Fund (CREF). Here benefit payments evolve according to the mortality experience of covered participants; see Weil and Fisher (1974) and Brown, Mitchell, Poterba, and Warshawsky (2001) for more information on the TIAA-CREF model.
} 
the underlying assets are held in risky assets. The buyer of the variable annuity can influence (in practice within some bounds) how the assets are invested in various asset categories (e.g. equities, bonds, real estate) while bearing both the risk and reward of that portfolio.

In the case of a (variable) investment-linked deferred annuity, the insurance premium generates lifelong payments which begin at some future age $K$, i.e. the end of the deferral period. We denote the value of a FU at time $K$ as $Z_{K}$. For an annuity contract signed at age $s(<K)$ which promises payment of $n_{s}(K)$ FUs at age $K$, the initial payout after the end of the deferral period, subject to survival, is given by $P O_{K}=n_{S}(K) Z_{K}$. Thereafter, the periodic payments $P O_{t+1}$ from the VILDA evolve according to:

$$
P O_{t+1}=P O_{t} \frac{1+R_{t+1}^{a}}{1+A I R}
$$

The equation shows that an updating rule relates the annuity payouts $P O_{t+1}$ in future periods to the previous payout $P O_{t}$ and the realized investment return $R_{t+1}^{a}$ of the assets underlying portfolio backing the annuity relative to the assumed interest rate $(A I R)$. The annuity payment rise when $R_{t+1}^{a}>A I R$; it falls when $R_{t+1}^{a}<A I R$; and it is constant when $R_{t+1}^{a}=A I R$. If the insurance pool is sufficiently large, the premium for the payout process can be calculated according to the actuarial principle of equivalence:

$$
P R_{s}=n_{s}(K) Z_{s} \ddot{a}_{s}(K ; A I R)
$$

where $\ddot{a}_{s}(K ; A I R)$ is the deferred annuity factor given by

$$
\ddot{a}_{s}(K ; A I R)=\delta p(s, K) \sum_{t=K}^{T} \frac{p(K, t)}{(1+A I R)^{t-K}}
$$

Here $\delta$ is the loading factor charged by the insurer. Given a mortality table to price the annuity, $p(s, K)$ is the cumulative survival probability between purchase age $s$ and the deferral age $K$, and $p(K, t)$ is the cumulative survival probability between age $K$ and $t$. The retiree's maximum 
age is $T$.

In contrast to fixed immediate payout annuities, VILDA payouts depend on the asset allocation in the underlying fund, as well as the deferral period. The classic immediate fixed annuity is a special case, whereby the assets inside the annuity consist entirely of risk-free bonds, the $A I R$ is set equal to the riskless interest rate (i.e. $A I R=R_{f}$ ), and the deferral age $K$ equals the age of purchase. To illustrate the effects of deferral on VILDA annuity benefits, Figure 1 shows for alternative deferral periods the range of payments (defined by the 5:95\% quantiles). These are derived by simulating $10,000,000$ payment paths of an annuity with a constant 50/50 allocation over risk-free bonds and risky equities. ${ }^{8}$

Figure 1 here

Here the payout possibility frontier for an immediate variable annuity is represented by the dotted line from age 65, which begins at $6.9 \%$ of the initial premium paid. Thereafter, the lower line (5\% quantile) slopes down with age, and if the retiree survives to age 80 , the payout rate would only be $3.8 \%$. This worsening risk over time results from the downside volatility of equity returns. The $95 \%$ quantile curve gradually increases to about $11.3 \%$ for the retiree who is still alive at age 80. The Figure illustrates two implications of deferring the annuity payouts. First, the spread for the first payment (assuming survival to age 65) is increasing in the deferral period. The range for a five-year deferral period is $6.2-11.6 \%$; for the 10 year deferral, it is 6.5 15.9\%. Second, conditional on survival, both the up- and the downside payout profiles are improved. We note that this comes at the cost of a larger chance of dying before the payments start.

\footnotetext{
${ }^{8}$ Here the risk-free rate is set to $2 \%$ p.a. and the gross equity returns are log-normally distributed with a mean of $6 \%$ percent and a standard deviation of 20\%. Annuity premiums are based on the 2007 U.S. female population mortality table as provided by the Human Mortality Database, incorporating a trend in mortality rates calibrated to the changes in U.S. female mortality between years 1933 and 2007 (see Section 4.2 for details). The AIR is set to 4\%.
} 


\section{VILDAs under Systematic Mortality Risk}

\subsection{Price and Benefit Dynamics}

VILDAs transfer investment risks to the annuitants. Longevity risks, however, still remain with the insurer. While pooling a sufficient number of annuitants allows the insurer to manage the idiosyncratic part of longevity risk, it does not provide a hedge against the systematic longevity risk, for which other means are required. In this paper we focus on two approaches VILDA providers have at hand for managing systematic mortality risks: insurer self-insurance, and risk pool participation.

Following the self-insurance strategy, the provider retains the systematic longevity risk and sets the VILDA price (measured in FUs) to ensure a sufficiently high probability that the number of FUs paid to the annuitants does not exceed the number of FUs in the provider's reserves. We define the adequately high level as $\alpha$. Formally, the price $\Pi_{\alpha}$ for the risk quantile $\alpha$ is the number of FUs that satisfies the following condition:

$$
\mathbb{P}\left\{\tilde{p}(t, K) \sum_{s=K}^{T} \tilde{p}(K, s)\left(\frac{1}{1+A I R}\right)^{s-K} \leq \Pi_{\alpha} \mid \mathcal{F}_{t}\right\}=\alpha, \quad t<K
$$

Again, $\tilde{p}(x, y)$ is the cumulative survival rate between age $x$ and age $y, K$ is the deferral age, $T$ is the assumed maximum possible survival age, $A I R$ is the assumed interest rate, and $\mathcal{F}_{t}$ is the information set at time $t$. By contrast to the assumptions in Section 2, survival rates $\tilde{p}$ are stochastic and depend on the state of the mortality process at time $t$ as well as its future development. Accordingly the annuity prices also depend on the state of the mortality process. Obviously, these prices are not actuarially fair but include premiums for insuring against adverse mortality developments. 
When following the participation strategy, we assume that VILDA providers charge a fair price based on the actuarial principle of equivalence for new annuity purchases. Hence, at time $t$ $(\mathrm{t}<\mathrm{K})$, the price of a VILDA $\Pi_{t}$, is given by

$$
\Pi_{t}=\mathbb{E}\left[\tilde{p}(t, K) \sum_{s=K}^{T} \tilde{p}(K, s)\left(\frac{1}{1+A I R}\right)^{s-K} \mid \mathcal{F}_{t}\right], \quad t<K
$$

At the same time, unanticipated future mortality developments will be passed through to the annuitants by adjusting their stock of previously purchased claims to FU payments. Let $n_{t}(K)$ again denote the number of FUs payable at age $K$, which the annuitant accumulated until time $t$. At time $t+1$, in order to still be able to cover the VILDA liability with the reserves built up at the time the VILDA was sold, the provider must adjust the promised number of FUs due at age $K$ according to the following:

$$
n_{t+1}(K)=n_{t}(K) A F_{t+1}=n_{t}(K) \frac{\Pi_{t}}{\Pi_{t+1} p_{t}},
$$

where $p_{t}$ represents the realized one-period survival rate at age $t .^{9}$ If mortality develops as anticipated, the adjustment factor $A F_{t+1}$ is equal to 1 and the number of FUs promised to the annuitant does not change. By contrast, an unexpected decrease (increase) in mortality will result in an adjustment factor below (above) 1 and, hence, decrease (increase) the promised number of FUs. Once VILDA payouts commence, i.e. $t \geq K$, the adjustment factor is given by

$$
A F_{t+1}=\frac{\bar{\Pi}_{t}-1}{\bar{\Pi}_{t+1} p_{t}}
$$

where $\bar{\Pi}_{t}$ is the price of an immediate variable annuity due. Here, in case mortality develops as anticipated, the adjustment factor will collapse to $A F_{t+1}=(1+A I R)^{-1}$, representing the regular decay of the number of FUs paid to the annuitant.

\footnotetext{
${ }^{9}$ This can be shown based on a simple FU balance argument (see the Appendix).
} 


\subsection{Implied Loadings and Benefit Variation}

Next, we want to illustrate the quantitative impact of systematic mortality risk on the prices and the benefit structures of the two alternative VILDA types presented in the previous section. To this end, we have to first specify a model for stochastic mortality. Here, we adopt the parsimonious two-factor model by Cairns, Blake, and Dowd (2006b) where the logits of the conditional one-year mortality rates $\left(q_{x, t}\right)$ for age $x_{t}$ at time $t$ are presumed to evolve according to:

$$
\operatorname{logit}\left(q_{x, t}\right)=\log \left(\frac{q_{x, t}}{1-q_{x, t}}\right)=A_{0, t}+A_{1, t} x_{t}
$$

Here $A_{0, t}$ is a stochastic factor that influences mortality rates equally at all ages, and $A_{1, t}$ is a stochastic factor that drives age-dependent shocks in mortality rates. Moreover, the vector $A_{t}=\left(A_{0, t}, A_{1, t}\right)^{T}$ follows a two-dimensional random walk with drift:

$$
A_{t+1}=\tau+A_{t}+V Z_{t+1}
$$

where $\tau$ is the drift of $A_{t}, V$ is the lower triangular Cholesky matrix of the covariance $\Sigma$ of $A_{t}$ (i.e. $\Sigma=V^{T} V$ ), and $Z_{t+1}$ is a two-dimensional standard normal innovation. Using OLS regression, we calibrate this model to the Human Mortality Database for US females age 20-109 over the period 1933-2007. ${ }^{10}$ This produces the following point estimates: ${ }^{11}$

$$
\begin{gathered}
\hat{\tau}=\left(\begin{array}{r}
-0.0337497 \\
0.0003242
\end{array}\right), \\
\hat{A}_{0}=\left(\begin{array}{r}
-10.1502416 \\
0.0904819
\end{array}\right),
\end{gathered}
$$

and

\footnotetext{
${ }^{10}$ Specifically, we use the United States of America, Life tables (period 1x1), Females, Last modified: 13-Oct-2010, MPv5 (May07). See www.mortality.org.

${ }^{11}$ These are comparable in sign and magnitude to those reported by Cairns et al. (2006b) for males (age 60+).in England and Wales over 1982-2002. While these point estimates are subject to parameter uncertainty, we refrain from accounting for estimation errors for the sake of keeping the lifecycle model manageable.
} 


$$
\widehat{\Sigma}=\left(\begin{array}{rr}
0.0019766 & -0.0000291 \\
-0.0000291 & 0.0000006
\end{array}\right) .
$$

The implications of this stochastic mortality model may be observed in Figure 2, which presents the simulated distribution of the $t$-period survival probabilities for an individual initially aged 20. The graph shows that the probabilities of living to advanced ages exhibit significant dispersion. For example, the probability of attaining age 70 (i.e. $p(20,70)$ ) spans the range from $79-93 \%$, with a median of $87 \%$; the probability of surviving to age $100, p(20,100)$, spans the range $0.02-45 \%$, with a median of $9 \%$. These results suggest that the expected lifetime remaining from age 20 varies between 56.7 and 73.8 years, with a median of 64.5 years. This compares to $p(20,70)=80 \%$ and $p(20,100)=4 \%$ with an expected lifetime remaining from age 20 of 59.7 years, if we were to neglect both the trend and the volatility of the mortality process and use only $\hat{A}_{0}$ to derive a static life table as of age of 20. In other words, using this stochastic mortality model, future survival rates and years of life remaining are likely to exceed those derived from the deterministic scenario.

Figure 2 here

With this model for stochastic mortality at hand, we first assess the impact of systematic longevity risk on VILDA prices under the self-insurance strategy, where systematic longevity risk is borne by the insurer. To this end, we calculate the age-dependent implied loadings for preselected confidence levels $\alpha$ (see Equation 4). For each initial age, these are derived by sampling $10,000,000$ realizations of the stochastic mortality process until the terminal age (120). For each sample path we then calculate the expected number of FUs paid to an annuitant in order to derive the distribution of VILDA prices. To get an estimate of the implied loading, we subsequently relate the number of FUs paid at the quantile $\alpha$ to the average number of FUs paid. 
As shown in Figure 3, these price increases can be substantial, especially for younger annuitants. At age 20, for example, VILDA providers must charge loadings on top of the actuarially fair premium of around 32\% to maintain a 99.99\% confidence level (to be used in what follows). At the $99.5 \%$ confidence level, loadings must amount to over $20 \%$ for this age group. At later ages, the dispersion of possible future mortality outcomes decreases and so does the implied loading. Nevertheless at age 66, just before VILDA payments commence, the loadings required to meet the $99.99 \%$ (99.5\%) confidence level still amount to around $14 \%$ (9\%). Figure 3 here

Next we turn attention to participating VILDAs that transfer systematic longevity risk to the annuitants. Figure 4 presents the mean as well as the 5:95\% quantiles of the simulated adjustment factors for ages 20-120. The mean periodic adjustment factor, as discussed, is 1 until the deferral age 67 and then drops to $(1+A I R)^{-1}=(1+0.03)^{-1}=0.971$ for the remainder of the lifecycle (see Equations 6 and 7). Over almost the entire deferral period, the 5:95\% quantiles of the periodic adjustment factors span the range 0.98-1.02, meaning that (notional) claims to FU payments may increase/decrease by around $2 \%$ per period. Later, during the payout phase, this span widens to a maximum of 0.93-1.01 by age 105. Hence, while payments (measured in FUs) are projected to decrease by the factor of 0.971 per period, unexpected decreases in mortality might result in an additional periodic drop in FUs paid of 4\%; in the case of mortality increases, payments in FUs might actually rise by $1 \%$.

Figure 4 here

To assess the impact of accumulated adjustment factors on the benefits of participating VILDAs, Figure 5 presents the simulated distribution of actual FU payments relative to the expected number of FUs paid at a given age. Based on our simulations, at age 67, the initial 
number of FUs paid at the $5 \%$ quantile falls short of the expected value by around $11 \%$. At the 95\% quantile, on the other hand, the annuitant receives almost $14 \%$ more FUs. Over the subsequent years, the dispersion increases slowly, spanning the range -18-25\% at age 100 and 23-30\% just before the end of our projection at age 119.

Figure 5 here

\section{Integrating VILDAs into a Lifecycle Consumption and Portfolio Choice Model}

Next we draw out the lifecycle implications of including VILDAs in the household investment portfolio.

\subsection{Model and Calibration}

To this end, we build a discrete-time lifecycle consumption and portfolio choice model for a utility-maximizing household that draws time-separable CRRA utility from consumption and has access to incomplete markets for risk-free bonds, risky stocks, and VILDAs. The household's decision period begins at the age of 20 and ends at the outside age $(T)$ of 120 . Every year the household has to decide how much to consume $\left(C_{t}\right)$, how much of both liquid and annuitized wealth to invest in risk-free bonds ( $B_{t}$ and $Q_{t}$ respectively), and, prior to the retirement and deferral age $(K)$, how much to spend buying new annuities $\left(N_{t}\right)$. During the worklife, the household earns an exogenously-determined level of risky labor income, consisting of a deterministic trend $(\lambda)$ as well as permanent $\left(H_{t}\right)$ and transitory $\left(U_{t}\right)$ shocks. After retirement, the household receives a constant fraction of the last (permanent) salary as in the form of lifetime pension benefits. Throughout the lifecycle, the household is exposed to idiosyncratic as well as systematic longevity risk in the form of stochastic mortality rates. 
After normalizing by permanent labor income, the household’s optimization problem can be described by the following Bellman equation:

$$
J\left(W_{t}, L_{t}, A_{t}, t\right)=\max _{C_{t}, N_{t}, B_{t}, Q_{t}}\left[\frac{C_{t}^{1-\alpha}}{1-\alpha}+\beta p\left(t, A_{t}\right) \mathbb{E}_{t}\left[J\left(W_{t+1}, L_{t+1}, A_{t+1}, t+1\right) H_{t+1}^{1-\alpha}\right]\right]
$$

where $W_{t}$ represents (normalized) liquid wealth, $L_{t}$ the accumulated (normalized) annuity wealth, $\alpha$ the level of relative risk aversion, and $\beta$ the time discount rate. The two-dimensional variable $A_{t}$ describes the state of the Cairns/Blake/Dowd mortality process, defined in Section 3.2, and which - through Equation 8 - determines the state-dependent one-period survival rate $p\left(t, A_{t}\right)$. The state variables evolve according to:

$$
\begin{aligned}
& W_{t+1}=\left(W_{t}-C_{t}-N_{t}-B_{t}\right) \frac{R_{t+1}}{H_{t+1}}+B_{t} \frac{R_{f}}{H_{t+1}}+L_{t+1} \mathbb{I}\{t \geq K\}+\lambda(t) U_{t+1}, \\
& L_{t+1}=\left(\left(L_{t}+\frac{N_{t}}{\ddot{a}_{t, \kappa}\left(A_{t}\right)}-Q_{t}\right) \frac{R_{t+1}}{H_{t+1}}+Q_{t} \frac{R_{f}}{H_{t+1}}\right) A F(t), \\
& A_{t+1}=A_{t}+D_{t+1},
\end{aligned}
$$

where $R_{t+1}$ is the gross equity return and $R_{f}$ is the gross risk-free rate of return. $\mathbb{I}\{t \geq K\}$ is an indicator variable that takes the value 1 for $t \geq K$ and 0 otherwise, and $\ddot{a}_{t, \kappa}\left(A_{t}\right)$ is the age- and state-dependent price of a VILDA that starts paying benefits from age $K$. When VILDAs are of the participating type, $A F(t)$ is the benefit adjustment factor as defined in Equations 6 and 7. For non-participating VILDAs, $A F(t)$ is equal to 1 prior to $K$, and $(1+A I R)^{-1}$ subsequently. Finally, $D_{t+1}$ is the multivariate innovation to the mortality process according to Equation 9 . The policies undertaken must satisfy the following constraints:

$$
\begin{aligned}
& C_{t}, N_{t}, B_{t}, Q_{t} \geq 0 \\
& C_{t}+N_{t}+B_{t} \leq W_{t}
\end{aligned}
$$




$$
\begin{gathered}
Q_{t} \leq L_{t}+\frac{N_{t}}{\ddot{a}_{t, \kappa}\left(A_{t}\right)}, t<K ; \\
Q_{t} \leq L_{t}, t \geq K ; \\
N_{t}=0, t \geq K .
\end{gathered}
$$

In our calibration of the lifecycle model, we posit a coefficient of the relative risk aversion $(\alpha)$ of 5 , and a time discount rate $(\beta)$ of 0.96 . Retirement age is set to $K=67$ and the replacement rate is set to $40 \%$, i.e. the (normalized) retirement income is $0.4 \cdot \lambda(K-1)$ for $t \geq$ $K$. Our calibration of the remaining financial market and labor income parameters draws on Cocco, Gomes, and Maenhout (2005). We assume an annual gross risk-free rate of return $R_{f}$ of 1.02 on bonds, and gross equity returns $R_{t}$ are assumed to be independently log-normally distributed with mean 1.06 and standard deviation of 0.20 . The logs of transitory $\left(U_{t}\right)$ and permanent $\left(H_{t}\right)$ labor earnings shocks are uncorrelated and normally distributed with zero mean and standard deviations equal to $22.5 \%$ and $10 \%$, respectively. The mortality process is calibrated to the U.S. female population mortality tables over the period 1933-2007, as provided by the Human Mortality Database (see Section 3.2). Moreover, we posit that the pairwise correlations between shocks in mortality rates, labor income, and stock market return are all equal to zero. Finally, we set the assumed interest rate $(A I R)$ to $3 \%$, such that expected annuity payments in retirement are constant each period.

We solve the optimization problem using value function iteration as described in Carroll (2011). To this end, we discretize the following subset of the state space (wealth W, annuity L, mortality process $A_{0}$, mortality process $A_{1}$ ):

$$
[0,300] \times[0,10] \times[-0.5,0.5] \times[-0.01,0.01]
$$

using a double exponential grid with 64 points for the first (wealth) dimension, and equidistant grids for other dimensions with 40,8 , and 4 points, correspondingly. To evaluate the value 
function outside the supporting points, we employ linear tensor interpolation for the reason of stability and computational speed. Based on the optimal policy controls, we then simulate 1,000,000 cross-sectional independent lifecycles.

\subsection{Optimal Household Behavior with VILDAs}

Now, we describe optimal annuitization, asset allocation, and consumption profiles with VILDA annuities, assuming a static life-table (though stochastic individual survival). To this end, we set the covariance matrix of the mortality process $(\Sigma)$ to zero. ${ }^{12}$ In each case, we present the expected as well as the 5:95\% quantiles of the simulated distributions.

Table 1 reports annuity purchases (Panel A) as well as annuity payments (Panel B) at various ages. On average, households will begin to buy VILDAs in their late 30s. At age 40, $27 \%$ of the initial labor income is invested on average in VILDAs. Over the next two decades, the value of periodic annuity purchases rises to over half of the worker's first year labor income. At age 67, the last period when VILDAs can be purchased, these investments amount to slightly more than one times first-year labor income. Age 67 is also the point at which deferred VILDA payouts commence, and initially they amount to 1.84 times first labor income (on average). With expected investment returns slightly exceeding the $A I R$, average benefit payments slowly increase during retirement - to 2.07 (2.33) times the initial labor income at age 80 (100), conditional on survival. Looking at the tail of the annuity payment distribution, we find that even at the $5 \%$ quantile, VILDA payments come to a substantial $60 \%$ of first year's labor income.

\section{Table 1 here}

Next we report optimal lifecycle asset allocation patterns within the VILDA annuity portion of the portfolio. Table 2 indicates that, on average, households will hold most of VILDA assets in stocks for most of their active working lives; only in their 50s will they start shifting

\footnotetext{
${ }^{12}$ In this setting, $A_{t}$ is deterministic and, hence, the dimensionality of the state space reduces accordingly.
} 
more funds into bonds. This is a typical result for lifecycle asset allocation studies that account for periodic labor income that is not highly correlated with stock returns. ${ }^{13}$ During the retirement phase, the average allocation of VILDA assets to bonds remains at around $60 \%$. Households do, however, make use of the investment flexibility within the VILDAs. Looking at the $5 \%$ and the 95\% quantile of the bond share, there is substantial lifecycle variation: for instance at age 45 (50), between 0-64\% (0-61\%) of VILDA assets are held in bonds. This band narrows later in life, but bond fractions in retirement still range from 45 to $67 \%$.

Table 2 here

Table 3 summarizes the impact of having access to VILDAs on household consumption. Being able to insure against unexpected individual longevity risk reduces the need to build up financial reserves for financing retirement. Accordingly, households which can access VILDAs during their worklives are able to maintain higher consumption levels over their entire lifetimes. Compared to households that lack access to VILDAs, the rise in mean consumption is small early on, but it increases measurably during the worklife - from around $1.5 \%$ at age 20 , to over $5 \%$ in the late 50s and 60s. Subject to household survival, VILDAs prove to be of particular value late in life. Households that do not buy longevity insurance tend to deplete their financial assets, but VILDA purchasers continue to receive annuity payments. Consequently, the gap in consumption opportunities increases even further toward the end of the lifecycle, on average amounting to over $16 \%$ at age 80 and to more than $19 \%$ at age 100 . These enhanced consumption opportunities are rather stable over the whole distribution of possible consumption outcomes, in that the 5:95\% consumption quantiles are comparable in magnitude to the average consumption increments.

\section{Table 3 here}

${ }^{13}$ See, among others, Cocco, Gomes, and Maenhout (2005); and Horneff, Maurer, and Rogalla (2010). 


\subsection{The Impact of Systematic Mortality Risk on Household Behavior}

In this section, we examine the lifecycle implications of including VILDAs in the household portfolio including systematic mortality table risk. We discuss the implications of introducing either of the two previously-discussed VILDA types (with and without participation) on households' optimal profiles of consumption, annuitization, and asset allocation within VILDA annuities, assuming the stochastic evolution process for mortality developed above. In each case, we again present the expected as well as the 5:95\% quantiles of the simulated distributions.

The pattern of variable annuity purchases and payouts at various ages is summarized in Table 4. An average investor with access to participating VILDAs will begin buying these in his late 30s; at age 40 , periodic annuity purchases amount to $10 \%$ of his first-year's labor income. Purchases continue to rise to around 55\% of initial labor income over the next period, and then they remain almost constant over the following two decades. Only at age 67, the end of the deferral period, will the investor boost investments to 1.2 times initial labor income (as this is the last opportunity to purchase additional VILDAs). Average initial benefits amount to about 1.7 times first-year labor income. As expected investment returns slightly exceed the AIR, VILDA benefits slowly increase to 1.96 (2.2) times initial labor income by age 80 (100).

\section{Table 4 here}

If consumers are only able to purchase non-participating VILDAs calculated based on the quantile pricing approach, they will postpone annuitization by an average of approximately 5 years. They begin buying the non-participating VILDAs in their early 40s, trading off relatively higher prices resulting from the higher chance of being alive when benefits commence, versus relatively lower prices due to lower exposure to systematic mortality risk. Wishing to make up 
for delayed annuity purchases, investors in their late 40s must shift more financial assets into nonparticipating annuities, compared to investors with access to participating VILDAs. Wishing to make up for delayed annuity purchases, investors in their late 40’s must shift more financial assets into annuities than would investors with access to participating VILDAs. At age 50 (60), the average household invests a sum equivalent to around $89 \%$ (107\%) of the first-year labor income into new non-participating VILDA purchases, 60\% (100\%) more than consumers buying participating VILDAs. Again, purchases peak at age 67 (1.39 times first-year labor income), marking the last time investors can purchase additional VILDAs. Despite having spent substantially more on new annuities over the last two decades of their working lives, the average household's initial non-participating VILDA benefits worth 1.6 times first-year labor income fall short of those holding participating VILDAs, by almost $10 \%$. This difference persists to the end of the lifecycle.

Participating VILDAs must, on average, outperform non-participating VILDAs due to the lack of loading related to systematic mortality risks; nevertheless their lower price comes at the cost of exposing annuitants to systematic mortality risk. As discussed in Section 3.2, this could result in measurably lower VILDA benefits, especially later in the lifecycle. Hence, it is of interest to see how the distributional tails of the benefit payments for both types of annuities relate to each other. Panel B of Table 4 shows that participating VILDAs, despite exposing annuitants to systematic mortality risk, provide benefits that exceed those of non-participating annuities at the 5th as well as the 95th percentiles. Apparently, the lower price of participating VILDAs allows households to buy enough additional longevity insurance to more than compensate for possible benefit reductions caused by decreasing general mortality. 
The asset allocation patterns in Table 5 indicate that neither the introduction of systematic mortality risks nor the specific VILDA design (participating vs. non-participating) has a major impact on the distribution of VILDA funds over the alternative asset classes. Again, average VILDA bond fractions increase toward the end of the worklife and remain stable during retirement, while the bond share dispersion remains between $40-70 \%$ in retirement.

\section{Table 5 here}

The welfare-enhancing effects of having access to VILDAs are represented in Table 6 where we summarize the consumption increases available to consumers in various scenarios. Already by age 20, the household that purchases participating VILDAs are (on average) able to afford about $1.3 \%$ more consumption, compared to their counterparts in a world without VILDAs. This number rises to around 3.5\% at age 40 and to over $4 \%$ by age 60 . This can be attributed to the lower need to build up (liquid) wealth to finance consumption at very high ages when being insured against unexpected individual longevity. As in the last section without systematic mortality risk, VILDAs prove to be particularly valuable for those who attain advanced ages. Average consumption of households aged 80 that have VILDA income exceeds consumption of equally aged households in a no-VILDA world by $12.5 \%$, a number that increases to above $25 \%$ for those who reach age 100 . Again, we find these enhancements of consumption opportunities to be rather stable over the whole distribution of possible consumption outcomes.

\section{Table 6 here}

Having access to non-participating VILDAs also enables households to afford higher consumption over the whole lifecycle. As previously discussed, however, the substantial loadings resulting from the VILDA provider's need to self-insure against adverse systematic 
mortality developments significantly drive up VILDA prices. While spending more of their financial resources on VILDAs, households acquire lower benefits. This increases the need for liquid wealth later in life. Both effects result in lower average excess consumption compared to households with access to participating VILDAs. At age 20, average consumption is just less than $1 \%$ above that of households in a world without VILDAs. At age 60 , this difference only comes to about $2.3 \%$ (and $18.4 \%$ at age 100 ); excess average consumption falls short by $7 \%$ compared to households that own participating VILDAs. Looking at the tails, we again find comparably stable rates of excess consumption over the whole distribution of consumption outcomes.

In our set-up, despite exposing individuals to systematic mortality risks, participating VILDAs outperform non-participating VILDAs consumption-wise and hence should be preferred by households seeking to maximize utility from consumption. This is undoubtedly related to the substantial loadings that many providers charge in order to self-insure against the systematic longevity risk in non-participating VILDAs. Against this background, it is of interest to estimate the maximum premium that households would be willing to pay in order to be relieved of systematic mortality risks. For various ages and wealth levels, these premiums are presented in Table 7. To calculate these numbers, we solve for the loading charge in excess of the actuarially fair price of a non-participating VILDA that equates the utility drawn from the non-participating VILDA with the utility from a participating VILDA. Here we identify two effects: break-even loadings are increasing in the household's age, but decreasing in wealth. At age 40, a household with wealth amounting to twice first-year labor income would be willing to pay a premium of $1.52 \%$ on an actuarially fair (non-participating) VILDA price to insure against systematic longevity risk. While systematic mortality risks are higher for younger households (as 
per Section 3.2), they affect households financially only in the remote future. For this reason, they are outweighed by more imminent financial risks including labor income shocks. As retirement and deferral age near, the relative importance of systematic mortality risk increases and so does the household's willingness to pay for insurance. At age 65, for example, someone with the same wealth level (twice first-year labor income) would pay a premium of $7.7 \%$. With increasing wealth, households are less dependent on VILDAs for financing consumption in retirement and, hence, less willing to pay for stable VILDA payouts. Households with wealth of five times first-year labor income at age 40 (65) would only accept a premium of $0.69 \%$ (4.79\%) over the actuarially fair (non-participating) VILDA price.

Table 7 here

These results have an important implication for risk management by VILDA providers. First, VILDAs are likely to be usefully targeted at younger households, since this group is most likely to profit from the benefit of deferral. Second, this group may not be willing to pay for insurance against systematic mortality risk. Unless insurers have access to inexpensive hedges against systematic longevity risks, annuitants may be better off by bearing systematic mortality risk themselves via participating VILDAs.

\section{Conclusions}

This paper has discussed the key role of variable investment-linked deferred annuities (VILDAs) in household portfolio and consumption choices over the lifecycle. Inasmuch as their payments are deferred, VILDAs can be viewed as a privately-financed complement to governmental social security schemes. Permitting investment choice within VILDAs gives households greater flexibility to achieve their individually-optimal asset mixes, while permitting 
annuity providers to transfer investment risk back to the purchaser pool. Of special interest is the performance of VILDAs under both deterministic and stochastic mortality processes, and we explore two approaches to managing systematic mortality risks which do not rely on financial markets or other hedging instruments. Consistent with what is empirically observed, some annuity providers elect to self-insure their position by demanding higher than actuarially fair premiums, while others can transfer systematic mortality risks to their buyers by adjusting payouts as actual mortality developments unfold.

Our results imply that households benefit from gaining access to VILDAs, as measured by markedly higher consumption over the entire lifecycle. Moreover, households can use the flexibility of VILDAs to invest significant portions of their annuity assets in equities. We also show that the self-insurance approach to managing systematic mortality risks leads to substantial annuity loadings that may exceed 30\% for younger annuitants. Nevertheless, households are still better off with than without VILDAs. Given the choice, however, many households will prefer to participate in systematic mortality risk unless the insurer can hedge them at a significantly lower price. Depending on their age and wealth, consumer reservation loadings on the actuarially fair (non-participating) VILDA price vary between 0.5 and 8\%. If financial markets are thin and do not provide insurers with many hedging instruments in this price range, providers may seek to concentrate on their core competence - pooling idiosyncratic longevity risk - and transfer systematic mortality risk to annuitants. 


\section{Appendix}

When an annuity provider reacts to mortality changes by adjusting the benefits, we assume that the pool will be fully funded at all times. Let us denote the number of individuals in the pool that purchase a VILDA at time $t(<K)$ as $M_{t}$. Furthermore, let $n_{t}(K)$ be the promised number of fund units payable to each annuitant at time $K$ as of time $t$, and $\ddot{a}_{t, K}$ the price (in fund units) at time $t$ of a VILDA that will pay an initial benefit of one fund unit at time $K$, subsequently falling according to the $A I R$. Then, the total number of fund units in the annuity provider's reserves is equal to

$$
M_{t} \ddot{a}_{t, K} n_{t}(K)
$$

As the size of the pool and the annuity factor change, the annuity provider must change promised benefits to keep the pool fully funded. Abstracting from additional annuity purchases in the next period, we thus have the balance equation

$$
\begin{aligned}
M_{t+1} \ddot{a}_{t+1, K} n_{t+1}(K) & =M_{t} \ddot{a}_{t, K} n_{t}(K), \\
M_{t+1} & =M_{t} p_{t},
\end{aligned}
$$

which leads to the following evolution for the $n_{t}(K)$

$$
n_{t+1}(K)=n_{t}(K) \frac{\ddot{a}_{t, K}}{\ddot{a}_{t+1, K} p_{t}} .
$$

During the payout phase ( $t \geq K$ ), we must account for current payments that reduce the fund units stock by $M_{t} n_{t}(t)$. In this case, the balance equation takes the form

$$
\begin{aligned}
M_{t+1} \ddot{a}_{t+1, t+1} n_{t+1}(t+1) & =M_{t} \ddot{a}_{t, t} n_{t}(t)-M_{t} n_{t}(t) \\
M_{t+1} & =M_{t} p_{t}
\end{aligned}
$$

and therefore

$$
n_{t+1}(t+1)=n_{t}(t) \frac{\ddot{a}_{t, t}-1}{\ddot{a}_{t+1, t+1} p_{t}}
$$




\section{References}

Bell, A. (2011). Annuity Sales Keep Rising. LIMRA. May 18. http://www.lifeandhealthinsurancenews.com/News/2011/5/Pages/Annuity-Sales-KeepRising.aspx

Benartzi, S., Previtero, A. Thaler, R.H. (2011). Annuitization Puzzles. Journal of Economic Perspectives. (forthcoming).

Blake, D., Burrows, W. (2001). Survivor Bonds: Helping to Hedge Mortality Risk. Journal of Risk and Insurance 69, 339-348.

Brown, J.R., O.S. Mitchell, J.M. Poterba, and M.J. Warshawsky (2001). The Role of Annuity Markets in Financing Retirement, MIT Press, Cambridge, M.A.

Cairns, A., Blake, D., Dowd, K. (2006a). Pricing Death: Frameworks for the Valuation and Securitization of Mortality Risk. ASTIN Bulletin 36, 79-120.

Cairns, A., Blake, D., Dowd, K., (2006a). A Two-factor Model for Stochastic Mortality with Parameter Uncertainty: Theory and Calibration. Journal of Risk and Insurance 73, 687-718.

Cairns, A., Blake, D., Dowd, K., Coughlan, G., Epstein, D., Khalaf-Allah, M. (2010). A Framework for Forecasting Mortality Rates with an Application to Six Stochastic Mortality Models. Pension Institute Discussion Paper PI-0801, March 2010.

Carroll, Ch.D. (2011). Solution Methods for Microeconomic Dynamic Stochastic Optimization Problems. http://www.econ.jhu.edu/people/ccarroll/solvingmicrodsops.pdf (Accessed: 30 August 2011).

Cocco, J., Gomes, F., Maenhout, P., (2005). Consumption and Portfolio Choice over the Life Cycle. Review of Financial Studies 18, 491-533.

Cowley, A., Cummins, J.D. (2005). Securitization of Life Insurance Assets and Liabilities. The Journal of Risk and Insurance 72(2):193-226

Davidoff, T., Brown, J., Diamond, P. (2005). Annuities and Individual Welfare. American Economic Review 95, 1573-1590.

Fong, J.H.Y., Mitchell, O.S. Koh, B.S.K (2011). Longevity Risk Management in Singapore’s National Pension System. Journal of Risk and Insurance. (forthcoming).

Gale, W., Iwry, J. M., John, D. C., Walker, L. (2008). Increasing Annuitization of 401(k) Plans with Automatic Trial Income. Hamilton Project Discussion Paper. Washington, D.C.: The Retirement Security Project.

Gatzert, N., Wesker, H. (2010). The Impact of Natural Hedging on a Life Insurer's Risk Situation. Working Paper University of Erlangen.

Gomes, F.J., Kotlikoff, L.J. , Viceira, L. M. (2008). Optimal Life-Cycle Investing with Flexible Labor Supply: A Welfare Analysis of Life-Cycle Funds. American Economic Review 98(2): 297-303, May.

Horneff, W., Maurer, R. Mitchell, O.S., Dus, I. (2007). Following the Rules: Integrating Asset Allocation and Annuitization in Retirement Portfolios. Insurance: Mathematics and Economics. 42: 396408.

Horneff, W., Maurer, R., Mitchell, O.S., Stamos, M. (2009). Asset Allocation and Location over the Life Cycle with Survival-Contingent Payouts. Journal of Banking and Finance. (33) 9 September: 1688-1699. 
Horneff, W., Maurer, R. Mitchell, O.S., Stamos, M. (2010). Variable Payout Annuities and Dynamic Portfolio Choice in Retirement. Journal of Pension Economics and Finance. 9, April: 163-183.

Horneff, W., Maurer, R. Rogalla, R. (2010). Dynamic Portfolio Choice with Deferred Annuities. Journal of Banking and Finance 34: 2652-2664.

Hu, W.-Y., Scott, J.S.. (2007). Behavioral Obstacles in the Annuity Market. Financial Analysts Journal 63, 71-82.

Investment Company Institute (ICI). (2011). Retirement Assets Totaled \$18 Trillion. ICI News Release. Washington, D.C.: ICI.

Lee, R., Carter, L. (1992). Modeling and Forecasting U.S. Mortality. Journal of the American Statistical Association 87, 659-671.

McCarthy, D., Mitchell, O.S. (2010). International Adverse Selection in Life Insurance and Annuities. In: Tuljapurkar, S., Ogawa, N., Gauthier, A. (Eds.). Riding the Age Wave: Responses to Aging in Advanced Industrial States. New York: Springer, 119-135.

Milevsky, M., Promislow, D. (2001). Mortality derivatives and the option to annuitise. Insurance Mathematics \& Economics 29, 299-318.

Milevsky, M. (2005). Real Longevity Insurance with a Deductible: Introduction to Advanced-life Delayed Annuities (ALDA). North American Actuarial Journal 9, 109-122.

Piggott, J., Valdez, E., Detzel, B. (2005) The Simple Analytics of a Pooled Annuity Fund. Journal of Risk and Insurance. September 72(3): 497-521.

Pitacco, E., Denuit, M., Haberman, S., Olivieri, A. (2009). Modeling Longevity Dynamics for Pensions and Annuity Business. Oxford: Oxford University Press.

Renshaw, A., Haberman, S. (2003). Lee-Carter Mortality Forecasting with Age-specific Enhancement. Insurance: Mathematics and Economics 33, 255-272.

Schaus, S. L.(2005). Annuities Make a Comeback. Journal of Pension Benefits. 12(4): 34-38.

Weil, R.L., Fisher, L.. (1974). TIAA/CREF: Who Gets What? An Analysis of Wealth Transfers in a Variable Annuity. Journal of Business 47: 67-87.

Yaari, M. (1965). Uncertain Lifetime, Life Insurance, and the Theory of the Consumer. Review of Economic Studies 32, 137-150.

Yagi, T., Nishigaki, Y. (1993). The Inefficiency of Private Constant Annuities. Journal of Risk and Insurance 60, 385-412. 
Figure 1: VILDA Payout Ranges for Alternative Deferral Periods

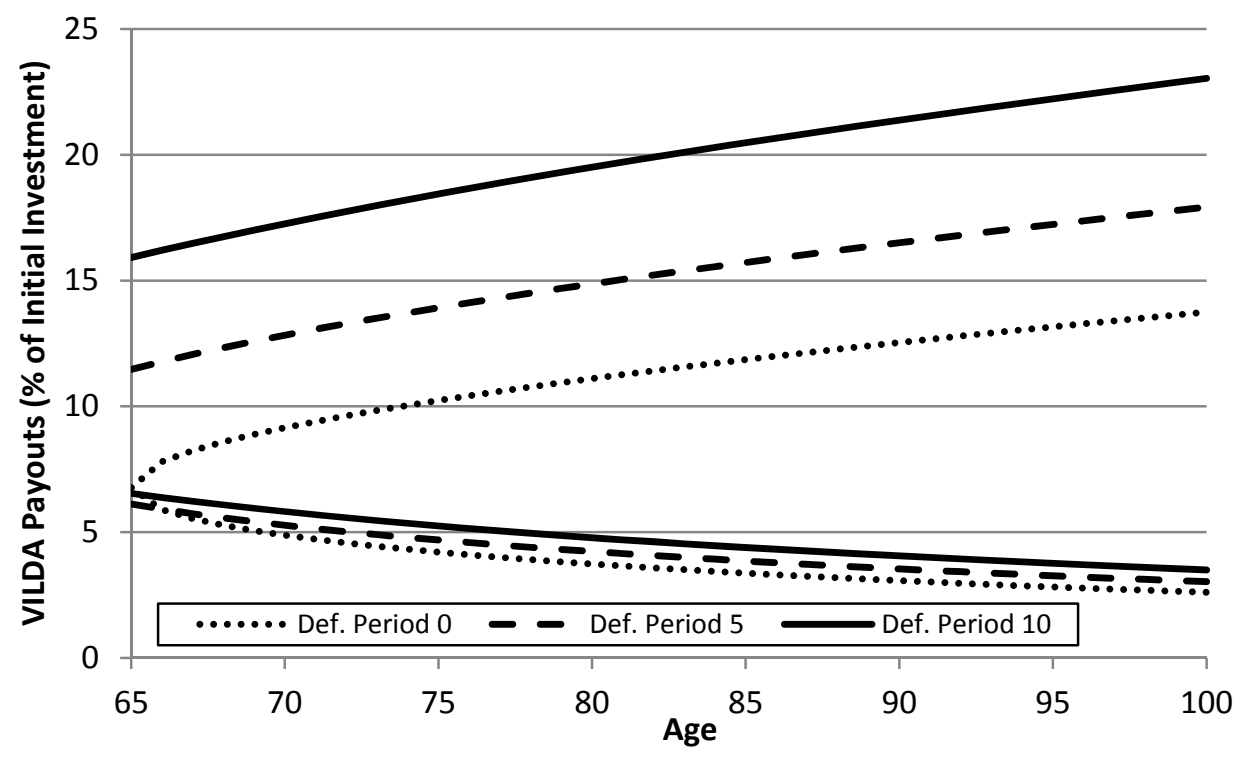

Notes: Range of VILDA payouts (in \% of initial VILDA investment) for deferral periods of 0, 5, and 10 years. Lower (upper) line represents 5\% (95\%) quantile. Payouts start at age 65. AIR = Exp. Fund Return = 4\%. Nonstochastic mortality. Source: Authors' calculations; see text.

Figure 2: Distribution of $t$-Period Survival Probability: Age 20 Female

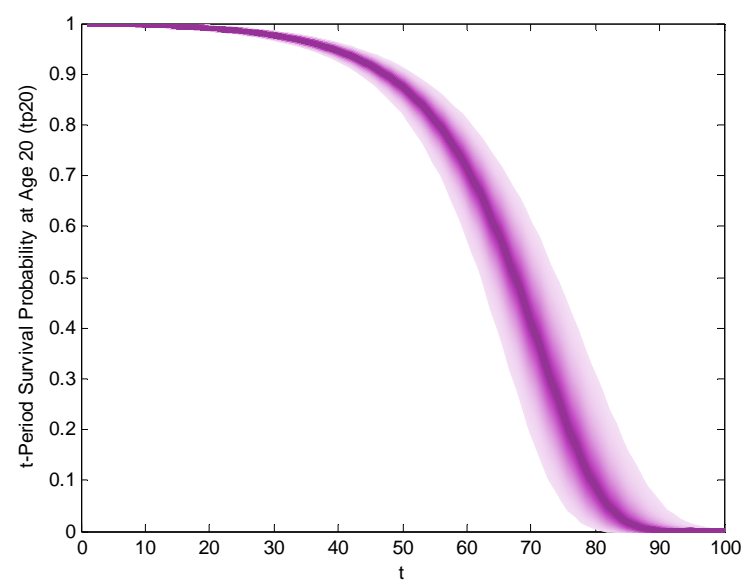

Notes: Simulated distribution of age-20 female $t$-period survival probabilities (99\%:1\%) based on Cairns et al. (2006b) mortality model with parameters (see text; $\mathrm{N}=10,000$ simulations). Darker areas represent higher probability mass. Source: Authors' calculations; see text. 
Figure 3: VILDA Solvency Confidence Levels and Implied Loadings

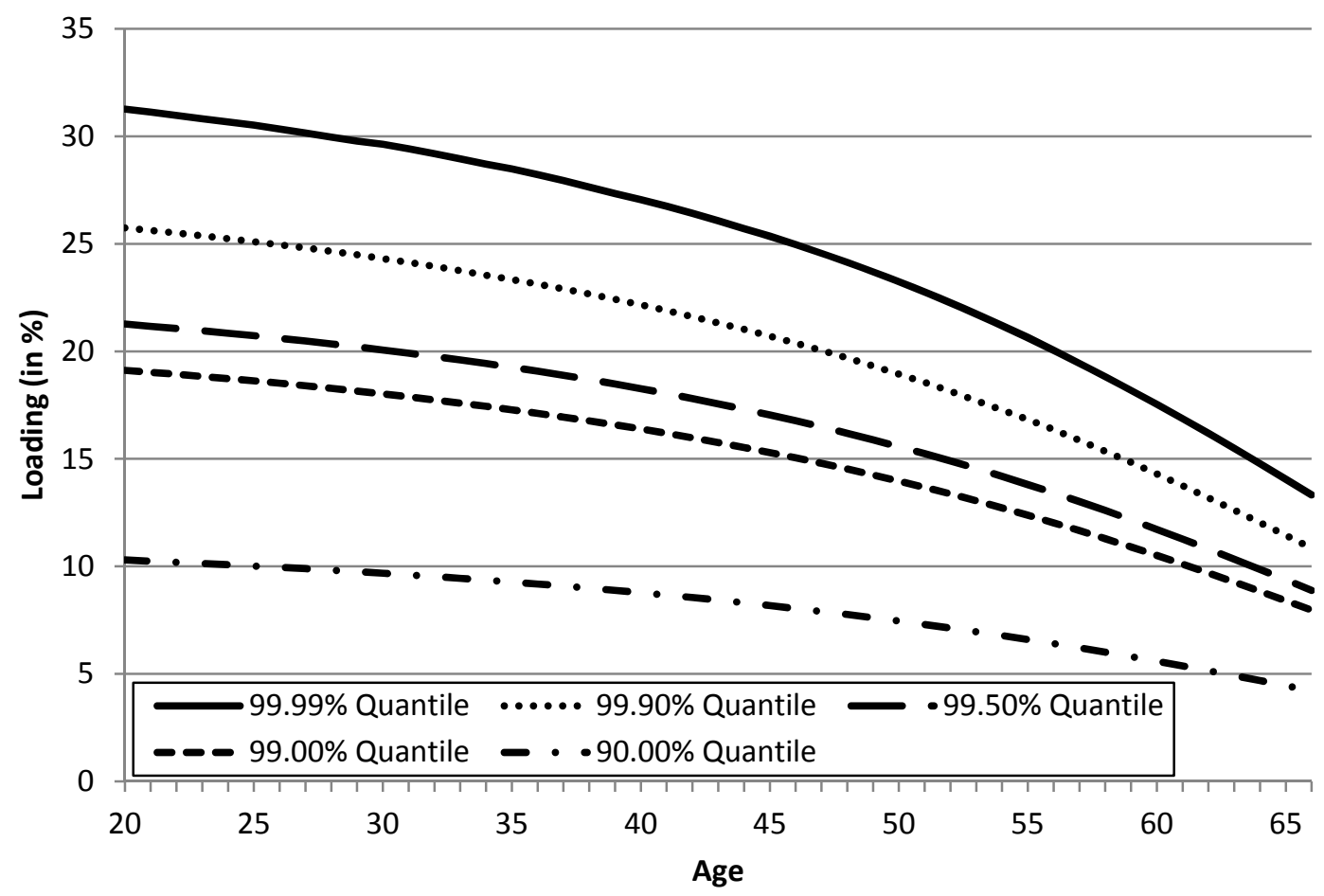

Notes: The implied loading represents the additional premium relative to the average number of required FUs that must be charged from US females for purchases at various ages to provide the VILDA at the specified confidence level. VILDA payments commence at age 67 with one initial FU and decrease thereafter according to the AIR (3\%). Confidence levels are based on the distribution of required FUs calculated for each of 10,000,000 simulated mortality paths using the Cairns et al. (2006) 2-factor stochastic mortality model fitted to US mortality tables from 1933-2007 (assumed maximum age is 120). Source: Authors' calculations; see text. 
Figure 4: Distribution of VILDA Periodic Adjustment Factors

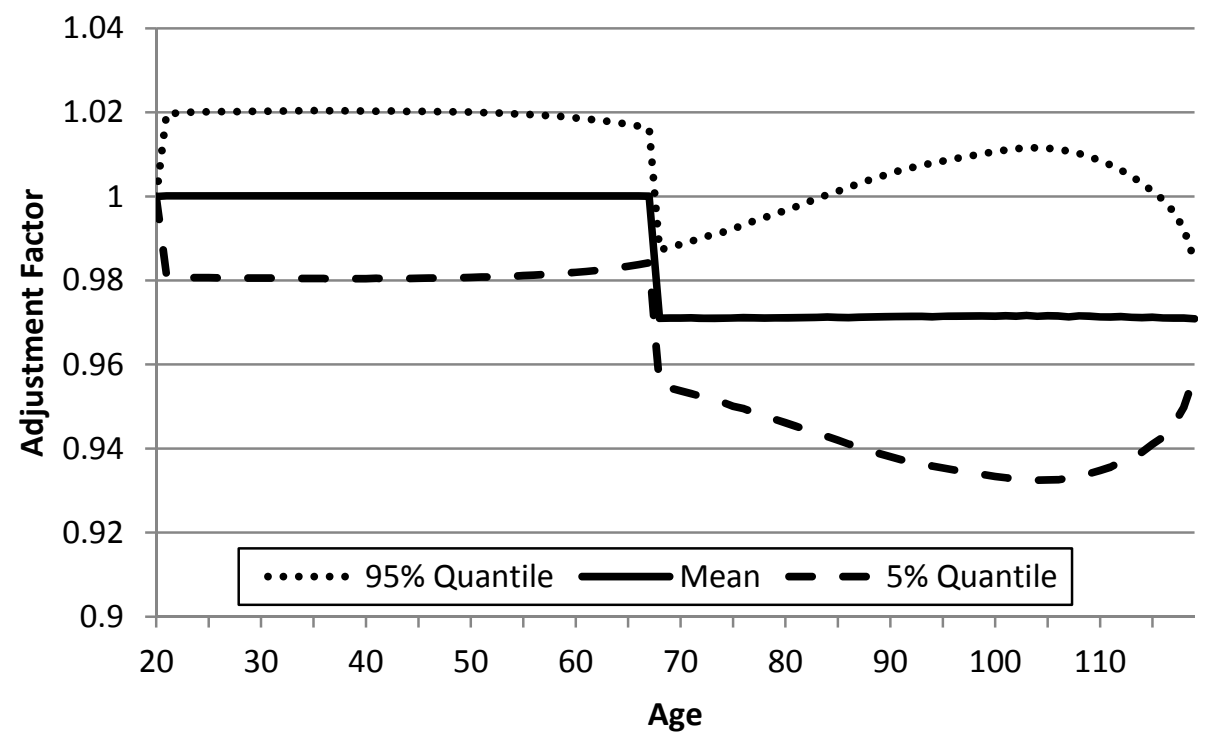

Notes: Adjustment Factors representing the year-on-year changes in benefit claims/benefit payments from participating VILDAs due to stochastic systematic mortality developments. Participating VILDA - in expectation pays one initial FU at age 67 and decreasing thereafter according to the AIR (3\%). Actual benefits vary through the Adjustment Factors with unexpected systematic mortality shocks. Stochastic mortality based on the Cairns et al. (2006) 2-factor model fitted to US mortality tables from 1933-2007 (assumed maximum age is 120). Source: Authors' calculations; see text. 
Figure 5: Distribution of VILDA Cumulated Adjustment Factors

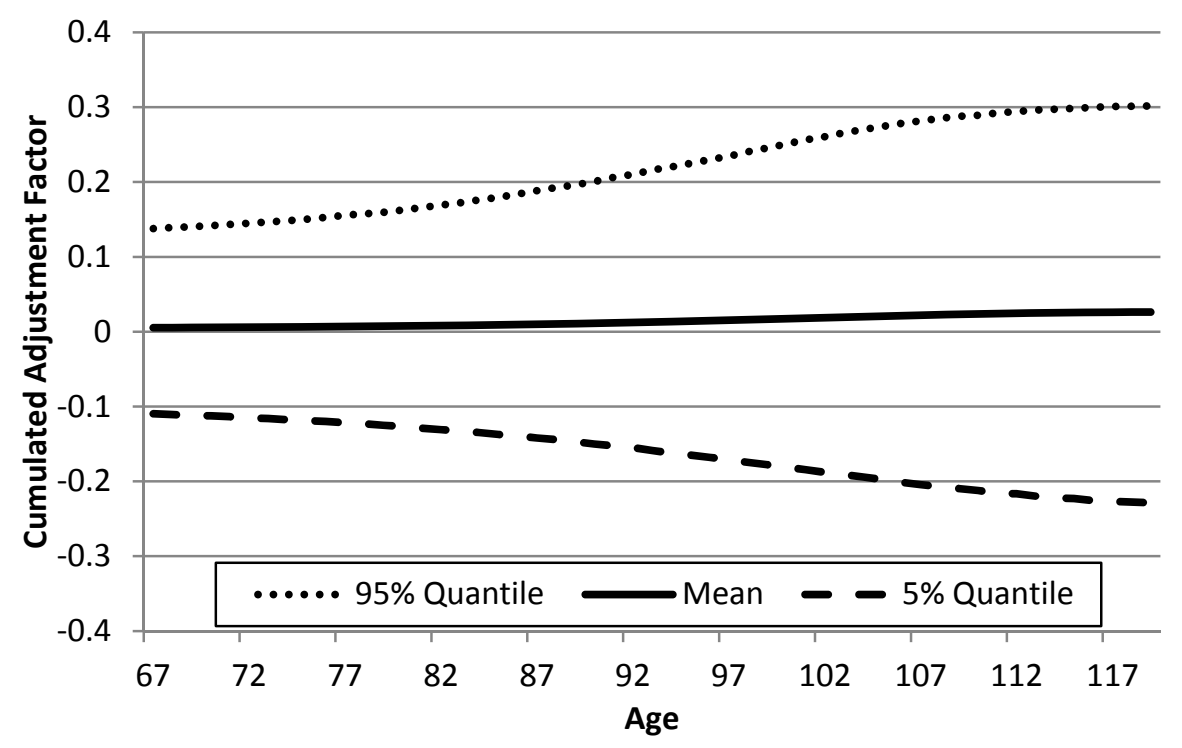

Notes: Cumulated Adjustment Factors representing the difference in benefit payments between participating VILDAs and otherwise equal non-participating VILDAs. Non-participating VILDA pays one initial FU at age 67 and decreasing thereafter according to the AIR (3\%). Participating VILDA - in expectation - pays one initial FU at age 67 and decreasing thereafter according to the AIR (3\%). Actual benefits vary with unexpected systematic mortality shocks. Stochastic mortality based on the Cairns et al. (2006) 2-factor model fitted to US mortality tables from 1933-2007 (assumed maximum age is 120). Source: Authors' calculations; see text. 
Table 1: Lifecycle VILDA Annuitization Patterns without Systematic Mortality Risk

\begin{tabular}{|c|c|c|c|}
\hline Age & $\begin{array}{c}5 \% \\
\text { Quantile }\end{array}$ & Mean & $\begin{array}{c}95 \% \\
\text { Quantile }\end{array}$ \\
\hline \multicolumn{4}{|c|}{ Panel A: Annuity Purchases } \\
\hline 30 & 0.00 & 0.00 & 0.00 \\
\hline 40 & 0.00 & 0.27 & 2.16 \\
\hline 50 & 0.08 & 0.50 & 1.22 \\
\hline 60 & 0.06 & 0.51 & 1.43 \\
\hline 67 & 0.21 & 1.06 & 2.79 \\
\hline \multicolumn{4}{|c|}{ Panel B: Annuity Payments } \\
\hline 67 & 0.59 & 1.84 & 4.08 \\
\hline 80 & 0.59 & 2.07 & 4.81 \\
\hline 90 & 0.58 & 2.19 & 5.26 \\
\hline 100 & 0.57 & 2.33 & 5.71 \\
\hline
\end{tabular}

Notes: Panel A: Money (as a multiple of initial labor income) invested in VILDAs at specified age. Panel B: Benefits (as a multiple of initial labor income) paid by accumulated VILDAs at specified age. VILDA pays one initial FU at age 67 and decreasing thereafter according to the AIR (3\%). Static mortality based on 2007 US female population table (assumed maximum age is 120). Source: Authors' calculations; see text.

Table 2: VILDA Bond Share without Systematic Mortality Risk

\begin{tabular}{ccccc}
\hline Age & & $\begin{array}{c}5 \% \\
\text { Quantile }\end{array}$ & Mean & $\begin{array}{c}95 \% \\
\text { Quantile }\end{array}$ \\
\cline { 1 - 1 } \cline { 5 - 5 } 45 & & 0.00 & 0.24 & 0.64 \\
50 & & 0.00 & 0.33 & 0.61 \\
60 & & 0.28 & 0.52 & 0.64 \\
67 & & 0.49 & 0.60 & 0.67 \\
80 & & 0.45 & 0.58 & 0.67 \\
90 & & 0.44 & 0.59 & 0.68 \\
100 & & 0.45 & 0.60 & 0.68 \\
\hline
\end{tabular}

Notes: Allocation of funds held in VILDAs to risk-free bonds at specified age. Static mortality based on 2007 US female population table (assumed maximum age is 120). Source: Authors' calculations; see text. 
Table 3: VILDA-related Consumption Increases without Systematic Mortality Risk

\begin{tabular}{|c|c|c|c|}
\hline Age & $\begin{array}{c}5 \% \\
\text { Quantile } \\
(\%)\end{array}$ & $\begin{array}{c}\text { Mean } \\
(\%)\end{array}$ & $\begin{array}{c}95 \% \\
\text { Quantile } \\
(\%)\end{array}$ \\
\hline 20 & 1.52 & 1.52 & 1.52 \\
\hline 40 & 3.17 & 4.35 & 4.40 \\
\hline 60 & 4.60 & 5.44 & 5.91 \\
\hline 80 & 17.13 & 16.36 & 16.38 \\
\hline 100 & 19.54 & 19.03 & 19.08 \\
\hline
\end{tabular}

Notes: Excess consumption (in \%) at specified age that household with access to VILDAs is able to afford compared to household in non-VILDA world. Static mortality based on 2007 US female population table (assumed maximum age is 120). Source: Authors' calculations; see text.

Table 4: Lifecycle VILDA Annuitization Patterns with Systematic Mortality Risk

\begin{tabular}{|c|c|c|c|c|c|c|}
\hline \multirow[b]{2}{*}{ Age } & \multicolumn{3}{|c|}{ Participating VILDA } & \multicolumn{3}{|c|}{ Non-participating VILDA } \\
\hline & $\begin{array}{c}5 \% \\
\text { Quantile }\end{array}$ & Mean & $\begin{array}{c}95 \% \\
\text { Quantile }\end{array}$ & $\begin{array}{c}5 \% \\
\text { Quantile }\end{array}$ & Mean & $\begin{array}{c}95 \% \\
\text { Quantile }\end{array}$ \\
\hline \multicolumn{7}{|c|}{ Panel A: Annuity Purchases } \\
\hline 30 & 0.00 & 0.00 & 0.00 & 0.00 & 0.00 & 0.00 \\
\hline 40 & 0.00 & 0.10 & 0.64 & 0.00 & 0.00 & 0.00 \\
\hline 50 & 0.07 & 0.55 & 1.52 & 0.00 & 0.89 & 3.75 \\
\hline 60 & 0.08 & 0.54 & 1.46 & 0.18 & 1.07 & 2.81 \\
\hline 67 & 0.25 & 1.20 & 3.17 & 0.33 & 1.39 & 3.49 \\
\hline \multicolumn{7}{|c|}{ Panel B: Annuity Payments } \\
\hline 67 & 0.54 & 1.73 & 3.85 & 0.50 & 1.60 & 3.55 \\
\hline 80 & 0.55 & 1.96 & 4.58 & 0.51 & 1.82 & 4.26 \\
\hline 90 & 0.54 & 2.08 & 5.02 & 0.50 & 1.93 & 4.64 \\
\hline 100 & 0.53 & 2.20 & 5.46 & 0.49 & 2.03 & 5.00 \\
\hline
\end{tabular}

Notes: Panel A: Money (as a multiple of initial labor income) invested in VILDAs at specified age. Panel B: Benefits (as a multiple of initial labor income) paid by accumulated VILDAs at specified age. Non-participating VILDA pays one initial FU at age 67 and decreasing thereafter according to the AIR (3\%). Participating VILDA in expectation - pays one initial FU at age 67 and decreasing thereafter according to the AIR (3\%). Actual benefits vary with unexpected systematic mortality shocks. Stochastic mortality based on the Cairns et al. (2006) 2-factor model fitted to US mortality tables from 1933-2007 (assumed maximum age is 120). Source: Authors' calculations; see text. 
Table 5: VILDA Bond Share with Systematic Mortality Risk

\begin{tabular}{|c|c|c|c|c|c|c|}
\hline \multirow[b]{2}{*}{ Age } & \multicolumn{3}{|c|}{ Participating VILDA } & \multicolumn{3}{|c|}{ Non-participating VILDA } \\
\hline & $\begin{array}{c}5 \% \\
\text { Quantile }\end{array}$ & Mean & $\begin{array}{c}95 \% \\
\text { Quantile }\end{array}$ & $\begin{array}{c}5 \% \\
\text { Quantile }\end{array}$ & Mean & $\begin{array}{c}95 \% \\
\text { Quantile }\end{array}$ \\
\hline 45 & 0.01 & 0.40 & 1.00 & 0.00 & 0.32 & 1.00 \\
\hline 50 & 0.00 & 0.35 & 0.65 & 0.00 & 0.69 & 1.00 \\
\hline 60 & 0.25 & 0.50 & 0.64 & 0.25 & 0.51 & 0.71 \\
\hline 67 & 0.49 & 0.60 & 0.67 & 0.46 & 0.59 & 0.68 \\
\hline 80 & 0.44 & 0.58 & 0.67 & 0.41 & 0.58 & 0.67 \\
\hline 90 & 0.43 & 0.59 & 0.68 & 0.39 & 0.59 & 0.68 \\
\hline 100 & 0.43 & 0.61 & 0.69 & 0.41 & 0.61 & 0.69 \\
\hline
\end{tabular}

Notes: Allocation of funds held in VILDAs to risk-free bonds at specified age. Non-participating VILDA pays one initial FU at age 67 and decreasing thereafter according to the AIR (3\%). Participating VILDA - in expectation pays one initial FU at age 67 and decreasing thereafter according to the AIR (3\%). Actual benefits vary with unexpected systematic mortality shocks. Stochastic mortality based on the Cairns et al. (2006) 2-factor model fitted to US mortality tables from 1933-2007 (assumed maximum age is 120). Source: Authors' calculations; see text.

Table 6: VILDA-related Consumption Increase with Systematic Mortality Risk

\begin{tabular}{|c|c|c|c|c|c|c|}
\hline \multirow[b]{2}{*}{ Age } & \multicolumn{3}{|c|}{ Participating VILDA } & \multicolumn{3}{|c|}{ Non-participating VILDA } \\
\hline & $\begin{array}{c}5 \% \\
\text { Quantile } \\
(\%)\end{array}$ & $\begin{array}{c}\text { Mean } \\
(\%)\end{array}$ & $\begin{array}{c}95 \% \\
\text { Quantile } \\
(\%)\end{array}$ & $\begin{array}{c}5 \% \\
\text { Quantile } \\
(\%)\end{array}$ & $\begin{array}{c}\text { Mean } \\
(\%)\end{array}$ & $\begin{array}{c}95 \% \\
\text { Quantile } \\
(\%)\end{array}$ \\
\hline 20 & 1.31 & 1.31 & 1.31 & 0.99 & 0.99 & 0.99 \\
\hline 40 & 3.25 & 3.58 & 3.73 & 2.38 & 2.49 & 2.43 \\
\hline 60 & 3.80 & 4.11 & 4.24 & 2.09 & 2.31 & 2.49 \\
\hline 80 & 12.39 & 12.53 & 12.53 & 7.44 & 7.18 & 7.07 \\
\hline 100 & 24.53 & 25.53 & 25.93 & 19.14 & 18.41 & 18.06 \\
\hline
\end{tabular}

Notes: Excess consumption (in \%) at specified age that household with access to VILDAs is able to afford compared to household in non-VILDA world. Non-participating VILDA pays one initial FU at age 67 and decreasing thereafter according to the AIR (3\%). Participating VILDA - in expectation - pays one initial FU at age 67 and decreasing thereafter according to the AIR (3\%). Actual benefits vary with unexpected systematic mortality shocks. Stochastic mortality based on the Cairns et al. (2006) 2-factor model fitted to US mortality tables from 1933-2007 (assumed maximum age is 120). Source: Authors' calculations; see text. 


\section{Table 7: Break-Even Loadings: VILDA Participation vs. Non-participation}

\begin{tabular}{|c|c|c|c|c|}
\hline \multirow[b]{2}{*}{ Age } & \multicolumn{4}{|c|}{ Wealth level ( $x$ initial labor income) } \\
\hline & $\begin{array}{c}2 \\
(\%)\end{array}$ & $\begin{array}{c}3 \\
(\%)\end{array}$ & $\begin{array}{c}4 \\
(\%)\end{array}$ & $\begin{array}{c}5 \\
(\%)\end{array}$ \\
\hline 40 & 1.52 & 1.19 & 1.02 & 0.69 \\
\hline 50 & 1.37 & 1.20 & 1.46 & 1.72 \\
\hline 60 & 3.84 & 3.63 & 3.68 & 3.57 \\
\hline 65 & 7.70 & 5.99 & 5.23 & 4.79 \\
\hline
\end{tabular}

Notes: Loadings represent the maximum price increase (in \%) relative to the actuarially fair price of a nonparticipating VILDA individuals are willing to accept in order to get access to non-participating instead of participating VILDAs. Non-participating VILDA pays one initial FU at age 67 and decreasing thereafter according to the AIR (3\%). Participating VILDA - in expectation - pays one initial FU at age 67 and decreasing thereafter according to the AIR (3\%). Actual benefits vary with unexpected systematic mortality shocks. Stochastic mortality based on the Cairns et al. (2006) 2-factor model fitted to US mortality tables from 1933-2007 (assumed maximum age is 120). Source: Authors' calculations; see text. 